\title{
Novel Intelligent and Sensorless Proportional Valve Control with Self-Learning Ability
}

\author{
Bayram Akdemir \\ Electrical and Electronics Engineering, Engineering Faculty, Selcuk University, Campus, Selcuklu, 42075 Konya, Turkey \\ Correspondence should be addressed to Bayram Akdemir; bywhite-ir@yandex.com.tr
}

Received 16 January 2016; Accepted 8 June 2016

Academic Editor: Chi Chiu Chan

Copyright (C) 2016 Bayram Akdemir. This is an open access article distributed under the Creative Commons Attribution License, which permits unrestricted use, distribution, and reproduction in any medium, provided the original work is properly cited.

\begin{abstract}
Linear control is widely used for any fluid or air flows in many automobile, robotics, and hydraulics applications. According to signal level, valve can be controlled linearly. But, for many valves, hydraulics or air is not easy to control proportionally because of flows dynamics. As a conventional solution, electronic driver has up and down limits. After manually settling up and down limits, control unit has proportional blind behavior between two points. This study offers a novel valve control method merging pulse width and amplitude modulation in the same structure. Proposed method uses low voltage AC signal to understand the valve position and uses pulse width modulation for power transfer to coil. DC level leads to controlling the valve and AC signal gives feedback related to core moving. Any amplitude demodulator gives core position as voltage. Control unit makes reconstruction using start and end points to obtain linearization at zero control signal and maximum control signal matched to minimum demodulated amplitude level. Proposed method includes self-learning abilities to keep controlling in hard environmental conditions such as dust, temperature, and corrosion. Thus, self-learning helps to provide precision control for hard conditions.
\end{abstract}

\section{Introduction}

Proportional valves in hydraulics and pneumatics are widely used in many applications and areas such as robotics, presses, and machines. Air or fluid flowing can be controlled easily according to requests as on or off. For many applications, only on and off are not enough for comfortable controlling. Although automatic control strategy is very complicated, proportional control ability opens a gate with many abilities [1-4]. Valves for hydraulics and air flows have more importance to control for many kinds of machines such as automobile, robotics, or planes in order to improve control ability and robustness; proportional control is widely used for flows controlling. But, especially in case of air, flow control is not easy because of gas features. Proportional pneumatic valves can have hysteresis levels as high as $15 \%$, which can wreak havoc on closed-loop control systems $[5,6]$. Another problem with proportional valves is that they often vary from one to another in terms of maximum flow and gain [7]. Gain is the rate of flow change to valve input current, and engineers require consistency and linearity for tight control. Two conventional ways, constant current or pulse with modulation (PWM) techniques, lead to simplifying control of valves. PWM and constant current control techniques have some weaknesses $[8,9]$. The proposed method has feedback abilities that come from its own structure so it leads to more precision control compared to conventional two ways. The proposed method has PWM structure for power transferring and alternative current $(\mathrm{AC})$ low voltage modulated signal superimposed to PWM signal to obtain core moving volume. In order to obtain robust control ability through the lifespan, self-learning ability algorithm is supported and discussed. Novel method measures core distance at zero control signal and maximum control signal at each running.

\section{Conventional Methods for Valve Controlling}

Two conventional methods, PWM and current source techniques, are simple control methods for proportional valve controls and both control circuits are so simple to apply. On the contrary, these methods have some weaknesses besides their simplicity. Pulse width modulation, which is a commonly used technique to control systems, is easily 
realizable with semiconductor switches. It has been already stated above that almost no power is dissipated by the switch in either on or off state. PWM makes inertial electrical devices controlling simple via modern electronic power switches. PWM can be used to adjust the total amount of power delivered to a load without losses normally incurred when a power transfer is limited by resistive means. The drawback is the pulsations defined by the duty cycle, switching frequency, and properties of the load. With a sufficiently high switching frequency and, when necessary, using additional passive electronic filters, the pulse train can be smoothed and average analog waveform recovered [10]. Figure 1 shows (a) PWM structure and (b) constant current driver structure. There are only two possible situations for the switching element. In both states, practically, power losses can be negligible $[11,12]$. Generated PWM signal occurs on the load as the same characteristics. In general, frequency is constant and pulse width is variable on time axis. Equation (1) shows output average voltage related to pulse width:

$$
V_{\text {average }}=V_{\mathrm{cc}} \times\left(\frac{\text { pulse width }}{\text { pulse length }}\right) .
$$

From the equation, generated (direct current) DC voltage can be varied using PWM modulation easily. On the contrary, output voltage not only is related to pulse width but also is related to $V_{c c}$ (power supply). Using this structure any valve can be controlled via varying voltage. In addition to power supply level, valve current cannot be controlled if it is not measured. These two weak points are difficulties of PWM.

Current source is a very old and robust model to avoid PWM weakness and electromagnetic interference. It is so simple to implement. Current flow is directly related to control voltage $\left(V_{x}\right)$ and cannot be changed even if $V_{\mathrm{cc}}$ changes in determined limits [13-15]. Changing power supply level does not affect the current level. Output current $\left(I_{c}\right)$ only depends on $V_{x}$ input signal. Equation (2) shows calculation of current flow. As soon as $R_{1}$ and $V_{x}$ are constant, there is no way to change the current:

$$
I_{c}=\frac{\left(V_{x}-V_{B E}\right)}{R_{1}} .
$$

On the contrary, current source can have high power loss on the controlling element $[16,17]$. Power dissipation must be calculated carefully to protect the device in order to carry on the running.

\section{System Details}

The proposed method uses PWM structure, amplitude modulation, and current source in the same structure for precision control. PWM structure is used for controlling power transfer. Amplitude modulation at medium frequency gives information about the core deep and core moving on the rail. In the valve, electromagnetic force and spring force are face to face with each other and core moving depends on electromagnetic force, so it is directly related to controlling current. So core traveling on the rail can be changed by adjusting the current level. If there could be a feedback from the core depth such as linear variable differential transformer (LVDT), it is possible to hold the core on the constant depth. When the core moves incorrectly, amplitude modulated feedback signal replies with a correction. An inductor is a passive electrical component used to store energy in a magnetic field. Inductor has a virtual resistance against frequency. In some determined conditions, inductance changes linearly. Inductance value can be calculated from

$$
L=\frac{\mu_{0} \mu_{r} N^{2} A}{l},
$$

where $L$ is inductance in henries, $\mu_{0}$ is permeability of free space, $N$ is number of turns, $A$ is area of cross section of the core in square meters, $l$ is length of core in meters, and $K$ is Nagaoka coefficient [18]. Inductor has a virtual resistance, namely, impedance, versus the frequency. Equation (4) shows inductor impedance:

$$
Z=2 \pi f L \text {. }
$$

Any change at the inductance affects the AC current flows through the core. Changed inductor helps us to evaluate the core distance given $h$ via amplitude modulation. For the proportional valve structure, there are three inductors to be explained. One of them is air core inductor, second one is magnetic metal envelope inductor, and core inductor comes from moving related to $l$. During the core moving, summed three inductors can be evaluated. $L_{0}$ is air core inductor, $L_{e}$ is envelope metal inductor, and $L_{c}$ is moving core inductor. Total $L$ is sum of the three inductors. Number of turns and all inductors can be explained as a function of $h$ moved distance through the hole. When $l$ equals $h, L_{0}$ and $L_{e}$ disappear and only $L_{c}$ occurs in total inductance. The starting point is at $h=0$; total inductance can be shown only by $L_{0}$ and $L_{e}$. Three kinds of inductors can be explained as a function of $h$ distance and $l$ as shown in Figure 2.

Through $h$ and $l$, number of turns can be spread linearly. From this point, $N$ is a linear function of $h$ and $l$ as shown by

$$
N_{h}=\frac{N \times h}{l} .
$$

Total inductance is sum of three inductor structures defined as $L_{0}, L_{e}$, and $L_{c}$. Total inductance is given by

$$
L_{T}=L_{0}+L_{e}+L_{c}
$$

Radii are different for all inductors. For $L_{0}$ radius can be written as $a$, for $L_{c}$ it can be written as $b$, and difference between $a$ and $b$ is for $L_{e}$ as shown in Figure 2. From (5), for every separated inductor, they can be expressed by (7), (8), and (9) for $L_{0}, L_{e}$, and $L_{c}$, respectively:

$$
\begin{aligned}
& L_{0}=\frac{\mu_{0} K(N(l-h) / l)^{2} \pi a^{2}}{l}, \\
& L_{e}=\frac{\mu_{0} \mu_{r} K(N(l-h) / l)^{2} \pi(b-a)^{2}}{l}, \\
& L_{c}=\frac{\mu_{0} \mu_{r} K(N h / l)^{2} \pi b^{2}}{l} .
\end{aligned}
$$




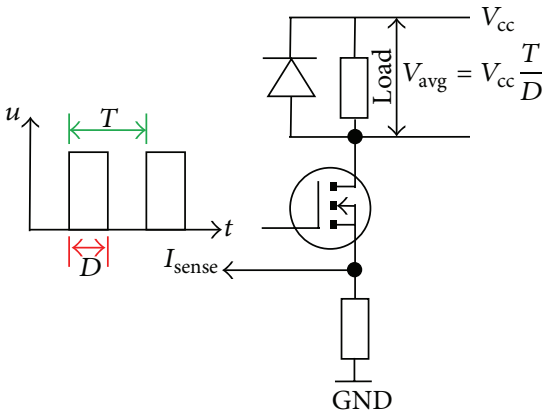

(a)

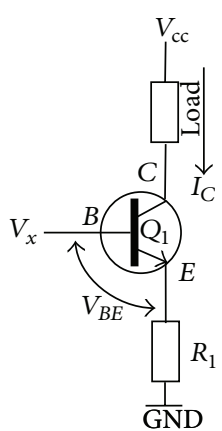

(b)

FIgURE 1: Proportional valve driving techniques: (a) PWM based driver; (b) constant current driver structure.

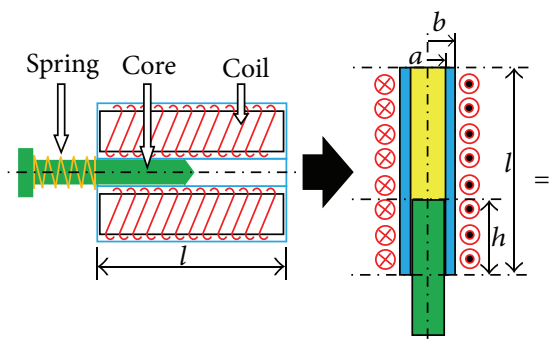

(a) (b)

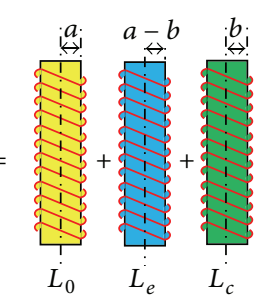

(c)

(d)

(e)
Figure 2: Valve is separated inductor structure: (a) side view; (b) vertical view; (c) $L_{0}$ simulates air core; (d) $L_{e}$ is constant core; (e) $L_{c}$ is variable inductor related to movable core.

From (5)-(9), total inductance can be expressed by

$$
\begin{aligned}
L_{T}= & \frac{\pi \mu_{0} K}{l^{3}}\left(N^{2}(l-h)^{2} a^{2}\right) \\
& +\left(\mu_{r} N^{2}(l-h)^{2}(b-a)^{2}\right)+\left(\mu_{r} N^{2} h^{2} b^{2}\right) .
\end{aligned}
$$

From the equations, inductance characteristic is a variable through $h$ and has virtual impedance which can be expressed as $Z$ in (4). $Z$ varies linearly related to inductance at constant frequency. Current has two parts and one of the parts is low voltage AC signal which is superimposed on DC running current. Current flows through the inductance, switching element, and current sense (resistor based). Low voltage DC current, superimposed with AC current, makes the core move. According to moving distance or moving depth, total inductance changes and changed inductance affects only $\mathrm{AC}$ current level. AC current level is a measurement of the core depth. Although $L_{e}$ impedance, $L_{c}$ impedance, and $L_{0}$ impedance are linearly through the frequency, $L_{T}$ is not linear. At any instant, $V_{a}$ can be calculated by (11) and AC current is related to total impedance including core resistance and $R_{1}$ and current equation is given by (12) as follows:

$$
\begin{aligned}
& V_{a_{\mathrm{AC}}}=\bar{I}_{\mathrm{AC}} \times R_{1}, \\
& \bar{I}_{a_{\mathrm{AC}}}=\frac{\bar{V}_{\mathrm{AC}}}{\left(R_{1}+R_{L}\right)+j 2 \pi f\left(L_{0}+L_{e}+L_{c}\right)_{1}},
\end{aligned}
$$

where $R_{1} \ll R_{L}$ and $R_{L} \ll j 2 \pi f L_{T}$ at $\mathrm{AC}$ conditions. For constant frequency, impedance has linear correlation with inductance. Output voltage, $V_{B}$, is related to inductance as nonlinear characteristics. $L_{T}$ behaves as an amplitude modulator and modulation characteristic is related to acts. Amplitude modulation is a simple modulation technique, which superimposes carrier signal and data signal [19, 20]. For proposed method, only carrier signal was scaled to use inductance. $C_{1}$ separates DC current and AC modulated signal from each other and leads AC signal to pass demodulator stage. Amplitude demodulation $[21,22]$ simply has one diode, resistor, and capacitor, as shown in Figure 3.

DC and AC signal have to move through the valve and DC current does not encounter any virtual impedance which is caused by frequency. AC signal has to overcome virtual impedance which is changing by core volume inside of the valve rail to occur in the outside as $V_{B}$. Output AC signal amplitude is at a different level according to $h$ depth. Demodulated signal over $C_{1}, D$ passes through the low pass filter $C_{2}$ and $R_{2}$. Figure 4 shows $V_{0}$ output voltage. As much as valve core moves, the obtained $V_{0}$ output voltage varies according to total $L_{T}$. Amplitude modulated frequency was chosen as $100 \mathrm{kHz}$ in order to avoid interference between PWM frequency and AC modulating signal. PWM running frequency was used as $10 \mathrm{kHz}$. Obtained feedback signal has negligible ripple at least as long as two times greater than PWM frequency [23]. In application 10 times greater AC signal is superimposed to PWM signal.

Although inductances of $L_{0}, L_{c}$, and $L_{e}$ have linear characteristics independently, at any time, three inductances are valid as sum of the inductances as $L_{T}$. So total characteristic is not linear and has to be corrected by the control unit. Table 1 is calculated virtually, and, from Table $1, L_{T}$ is not linear through $h$ distance. Total nonlinearity must be corrected using correction factor.

Figure 5 shows feedback signal related to $h$ distance and correction curve in the same graph. After correction on feedback signal, core moves behavior linearly. Learning method is based on inductance level at zero control voltage and stepped values span with 10\% PWM levels. If the moving depths are linear through the PWM, microcontroller based control unit obtains function in red line as a feedback 


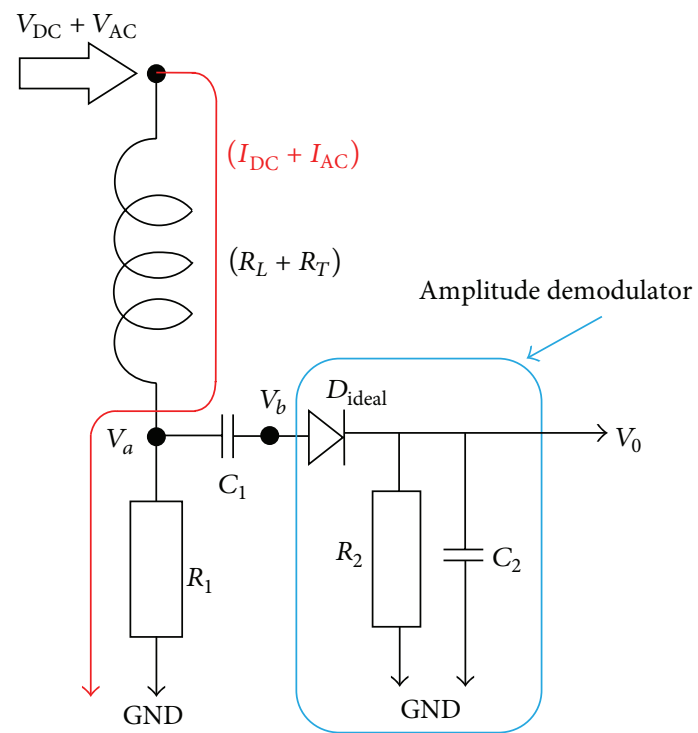

Figure 3: Amplitude demodulator to obtain feedback signal as $V_{0}$.

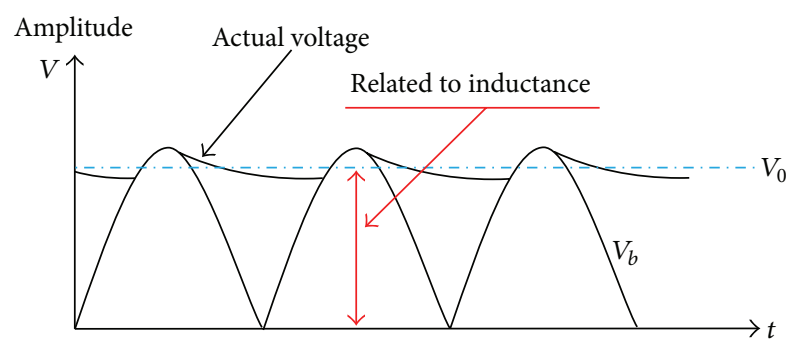

FIGURE 4: Demodulated AC signal from PWM as feedback signal.

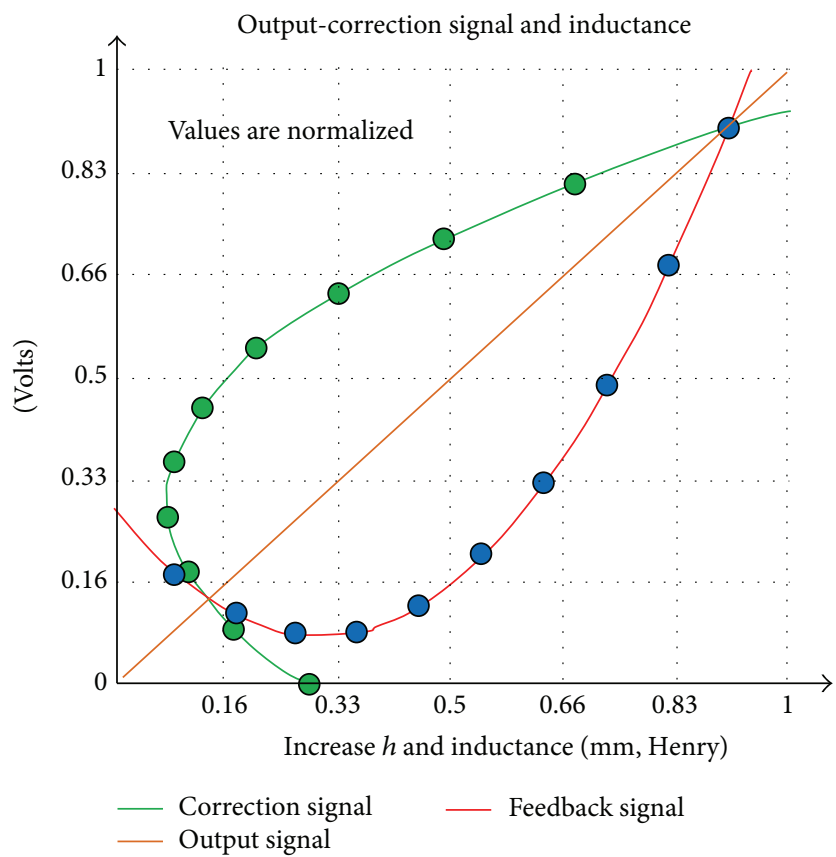

FIGURE 5: Output, feedback, and correction signal.
TABLE 1: Inductance changing through the distance.

Inductance changing through the core moving

\begin{tabular}{cccccc}
$h$ & $L_{0}$ & $L_{c}$ & $L_{e}$ & $L_{T}$ & Correction \\
\hline 0 & 0.1 & 0.8 & 0 & 0.9 & $\mathbf{0}$ \\
1 & 0.081 & 0.648 & 0.018 & 0.747 & $\mathbf{1 . 3 3 8 6 8 8}$ \\
2 & 0.064 & 0.512 & 0.072 & 0.648 & $\mathbf{3 . 0 8 6 4 2}$ \\
3 & 0.049 & 0.392 & 0.162 & 0.603 & $\mathbf{4 . 9 7 5 1 2 4}$ \\
4 & 0.036 & 0.288 & 0.288 & 0.612 & $\mathbf{6 . 5 3 5 9 4 8}$ \\
5 & 0.025 & 0.2 & 0.45 & 0.675 & $\mathbf{7 . 4 0 7 4 0 7}$ \\
6 & 0.016 & 0.128 & 0.648 & 0.792 & $\mathbf{7 . 5 7 5 7 5 8}$ \\
7 & 0.009 & 0.072 & 0.882 & 0.963 & $\mathbf{7 . 2 6 8 9 5 1}$ \\
8 & 0.004 & 0.032 & 1.152 & 1.188 & $\mathbf{6 . 7 3 4 0 0 7}$ \\
9 & 0.001 & 0.008 & 1.458 & 1.467 & $\mathbf{6 . 1 3 4 9 6 9}$ \\
10 & 0 & 0 & 1.8 & 1.8 & $\mathbf{5 . 5 5 5 5 5 6}$ \\
\hline
\end{tabular}

signal and calculates function in pink line to control valve proportionally and precisely.

Microcontroller based control techniques are widely used in literature [24, 25]. Microcontroller connections are shown in Figure 6. For every start, microcontroller scans valve behavior to compare the memorized one and present one. Then it refreshes the old information with present one to create new control characterization to minimize environmental effects such as temperature and dust. Possible changing on core inductance due to temperature and control characteristic is renewed for robustness.

Microcontroller unit records feedback signal at zero control voltage and saves this value as $L_{0}+L_{c}$. According to initial inductance, obtained feedback signal starts from maximum level and approaches zero when the core reaches end point. During the moving, feedback signal follows a second-order equation. From Table $1 L_{0}$ and $L_{c}$ start from 0.1 and 0.8 , respectively, and both end with zero. If core material has high $\mu_{r}$, effects of $L_{0}$ are so low and may be negligible. For real world application, $L_{0}$ has negligible effects on $L_{c}$ and $L_{e}$ and therefore $L_{T}$.

Microcontroller has two control strategies for selflearning. First way is very simple to apply and is based on blind learning. Microcontroller unit just saves feedback signals and control signals level as PWM level. End of the PWM spans from $0 \%$ to $100 \%$ with small steps; microcontroller connects the dots with lines and obtains control strategy from the curve line. Second way requires more math calculations than the first way. Microcontroller unit calculates a trajectory as a second-order equation and subtracts the core constant behavior characteristics during the run time. The rest of the feedback signal can be evaluated as moving depth by control unit. Both methods can be applicable and the first one is very simple learning way for robotics application avoiding back kinematics system behavior calculation.

\section{Implemented Circuit Results}

In this study, a linear valve behavior was used as measurement of the distance of coil. Thus, displacement of the coil can 


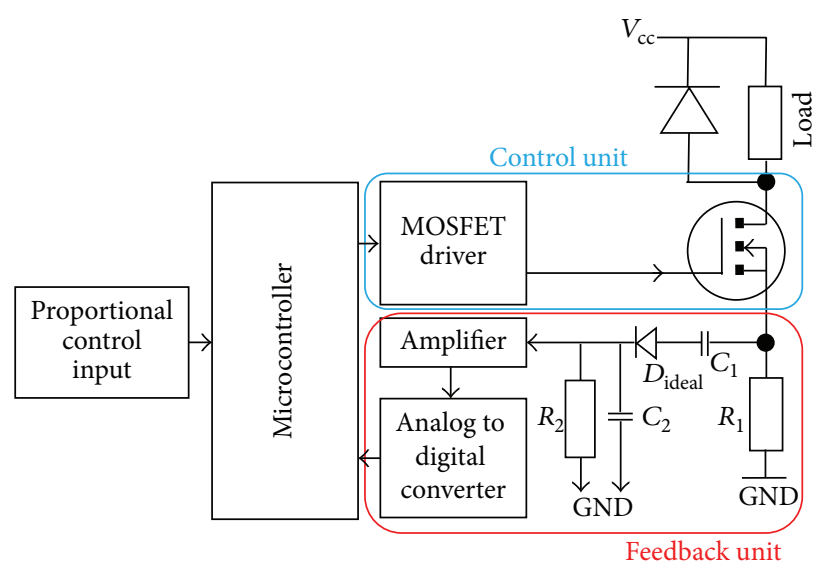

FIGURE 6: Block diagram of proposed method.

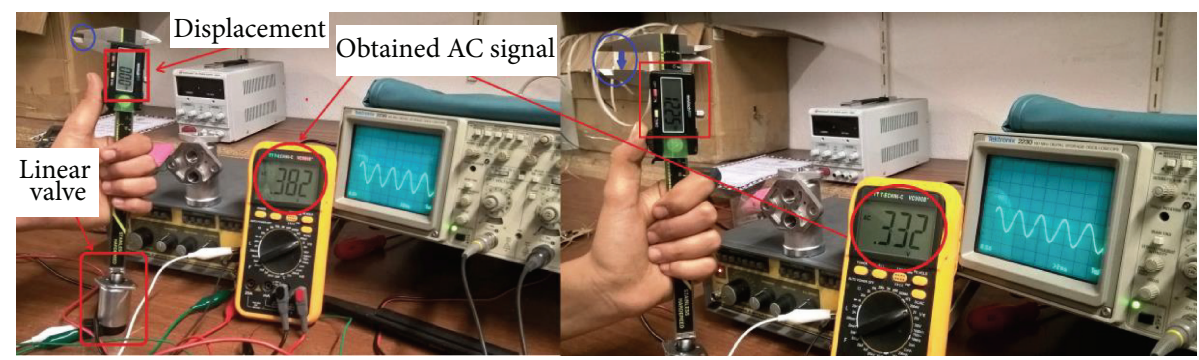

FIGURE 7: AC signal behavior related to displacement of the core.

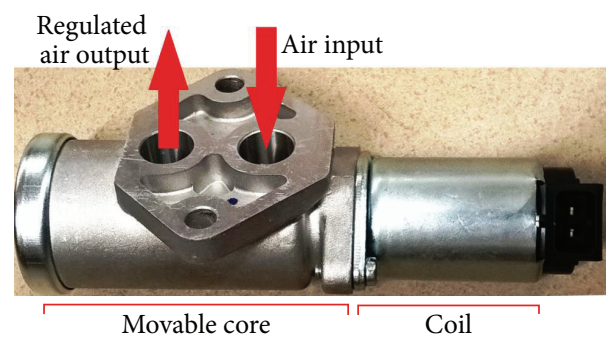

FIGURE 8: Linear valve (Opel Vectra) for sample application.

be calculated coil of the linear valve without using external measurement device. Table 2 shows the displacement and obtained AC signal due to moving. Figure 7 shows the implementation of the circuit.

According to study, inductance must be changed due to coil moving. Thus changed inductance affects the impedance of the coil under AC guide signal to measure the displacement. Table 2 shows measured real values due to coil moving. In order to implement the proposed method, air valve regulator for Opel Vectra was used. All of the car manufacturers use an air regulator to regulate the air input under idle running. Some of them prefer motor based regulator circuits; some of them use linear valve based solutions. Opel uses linear valve to regulate the air intake for idle running. Figure 8 shows tested linear valve for proposed method outcomes.

Preferred linear valve is highly robust and is designed for automobile sector. For the valve, total displacement is $5.9 \mathrm{~mm}$
TABLE 2: Measured and obtained values for the sample application of linear valve.

\begin{tabular}{lcc}
\hline & Min. & Max. \\
\hline Inductance $(\mathrm{mH})$ & $17.168 \mathrm{mH}$ & $17.558 \mathrm{mH}$ \\
Current $(\mathrm{A})$ & 0 & $1.2 \mathrm{~A}$ \\
AC signal $V_{\mathrm{RMS}}($ volt $)$ & 0.332 & 0.382 \\
Position $(\mathrm{mm})^{*}$ & 0 & 11.25 \\
\hline
\end{tabular}

${ }^{*}$ Note: be aware that position has offset value with different displacement.

and DC power supply necessary to run is $0-12$ Volts. Table 2 shows the obtained results after trying the proposed method. The obtained values from the application are $0.39 \mathrm{mH}$ and $50 \mathrm{mV}$ related to displacement.

From Table 2, changing inductance of the coil affects the impedance. Changed impedance only could affect the obtained AC signal. On the contrary, DC current cannot be affected by AC signal. Only DC current makes coil move and only AC signal gives response related to displacement. Total displacement is $5.9 \mathrm{~mm}$. AC signal varies from 0.332 to 0.382 . According to obtained values, a constant can be calculated using

$$
\begin{aligned}
& k=\frac{\Delta\left(V_{\mathrm{AC}}\right)}{\Delta(\mathrm{mm})}=\frac{V_{\mathrm{rms}}}{\mathrm{mm}}, \\
& k=\frac{0.382-0.332}{5.9}=\frac{8.47 m V_{\mathrm{rms}}}{\mathrm{mm}} .
\end{aligned}
$$


From (13), $k$, a constant related to moving core displacement, is calculated.

\section{Conclusion and Future Work}

In this study, novel approach is discussed to control any valve proportionally. The aim is to control the linear component without any external sensor to improve control ability. PWM and current mode driving techniques were merged and amplitude modulation was used for feedback to obtain core position information. This study involves not only proportional control but also sensorless position control for any electromagnetic core based valve. In particular, air valve controlling is not easy because of air behavior. This study helps eliminate some drawbacks such as temperature, hysteresis, and friction losses at any time. Air intake controlling for the cars could be robust in case of using the proposed method. Novel method makes robust control strategy in case of hard environmental conditions such as dust and temperature, because of the microcontroller scanning the valve at every starting. On the contrary, the proposed method creates a feedback related to displacement without external measurement device. The proposed method may offer open frame air valve controller to carry on control abilities continuously without any weakness through the lifespan. With learning ability, self-test strategies can be applied and service period can be reduced by self-learning.

\section{Competing Interests}

The author declares that there are no competing interests.

\section{Acknowledgments}

This study was supported by EEM Company which works in the sector of vertical transporting industries.

\section{References}

[1] Z. Entao and Y. Wenlin, "Research on the motion tracking feed forward control of hydraulic winch," in Proceedings of the International Conference on Computer Engineering and Applications, pp. 440-443, IACSIT, Manila, Philippines, June 2011.

[2] H. S. Dong, L. X. Ding, B. R. Feng, and W. Xi, "Research on the improvement of MPS coal mill loading hydraulic system," in Advanced Materials Research, vol. 452-453 of Management, Manufacturing and Materials Engineering, pp. 3-6, 2012.

[3] G. Granosik and J. Borenstein, "Minimizing air consumption of pneumatic actuators in mobile robots," in Proceedings of the IEEE International Conference on Robotics and Automation, pp. 3634-3639, IEEE, New Orleans, La, USA, April 2004.

[4] S. R. Pandian, Y. Hayakawa, Y. Kanazawa, Y. Kamoyama, and S. Kawamura, "Practical design of a sliding mode controller for pneumatic actuators," Journal of Dynamic Systems, Measurement and Control, Transactions of the ASME, vol. 119, no. 4, pp. 666-674, 1997.

[5] R. Marumo and M. O. Tokhi, "Modelling, simulation and proportional integral control of a pneumatic motor," Engineering Letters, vol. 13, no. 3, pp. 185-194, 2006.
[6] M. Sorli and S. Pastorelli, "Performance of a pneumatic force controlling servosystem: influence of valves conductance," Robotics and Autonomous Systems, vol. 30, no. 3, pp. 283-300, 2000.

[7] A. L. Hitchcox, Proportional Valve Overcomes Limitations, Pneumatic Systems, Hydraulics \& Pneumatics, 2003.

[8] M. K. Kazimierczuk, Pulse-Width Modulated DC-DC Power Converters, John Wiley \& Sons, London, UK, 1st edition, 2008.

[9] M. H. Rashid, The Power Electronic Handbook, Butterword Heinemann Press, Burlington, Vt, USA, 3rd edition, 2011.

[10] S. Maniktala, Switching Power Supply Design \& Optimization, McGraw-Hill, New York, NY, USA, 1st edition, 2004.

[11] K. Berringer, J. Marvin, and P. Perruchoud, "Semiconductor power losses in AC inverters," in Proceedings of the Conference Record of 30th IEEE-IAS Annual Meeting, vol. 1, pp. 882-888, Orlando, Fla, USA, October 1995.

[12] S. Clemente, "A simple tool for the selection of IGBTs for motor drives and UPSs," in Proceedings of the 10th Annual Applied Power Electronics Conference and Exposition (APEC '95), vol. 2, pp. 755-764, Dallas, Tex, USA, March 1995.

[13] C. T. Sah, Fundamentals of Solid State Electronics, World Scientific Publishing, Salem, Mass, USA, 4th edition, 1994.

[14] J. Millman and A. Grabel, Microelectronics, McGraw-Hill, New York, NY, USA, 1988.

[15] A. K. Dutta, "On the output impedance of a BJT Wilson current source," Microelectronics Journal, vol. 29, no. 3, pp. 67-70, 1998.

[16] M. Brown, Power Supply Cookbook, Newnes Publishing, Burlington, Mass, USA, 2nd edition, 2001.

[17] R. Liang and S. B. Dewan, "A low ripple power supply for high current magnet load," in Proceedings of the Industry Applications Society Annual Meeting, pp. 888-839, Houston, Tex, USA, October 1992.

[18] H. Nagaoka, “The inductance coefficients of solenoids," Journal of the College of Science, vol. 27, pp. 1-33, 1909.

[19] A. P. Godse and U. A. Bakshi, Electronics Engineering, Technical Publications Pune, Maharashtra, India, 1st edition, 2009.

[20] J. K. Harrison and P. E. Hammett, "Modulation, overmodulation, and occupied bandwidth: recommendations for the AM broadcast industry," in NAB Engineering Conference Proceedings, pp. 1-25, San Francisco, Calif, USA, September 1986.

[21] J. S. Chitode, Communication Engineering, Techical Publications Pune, Pune, India, 2nd edition, 2008.

[22] E. Bedrosian, "Amplitude demodulation of filtered AM/PM signals," IEEE Transactions on Information Theory, vol. 34, no. 6, pp. 1472-1482, 1988.

[23] C. E. Shannon and W. Weaver, The Mathematical Theory of Communication, 1998.

[24] B. Akdemir, S. Güneş, and I. T. Comlekciler, "Microcontroller compatible sealed lead acid battery remaining energy prediction using adaptive neural fuzzy inference system," in Proceedings of the International Conference on Web Information Systems and Mining (WISM '09), pp. 779-783, IEEE, Shanghai, China, November 2009.

[25] R. Akkaya and A. A. Kulaksiz, "A microcontroller-based standalone photovoltaic power system for residential appliances," Applied Energy, vol. 78, no. 4, pp. 419-431, 2004. 


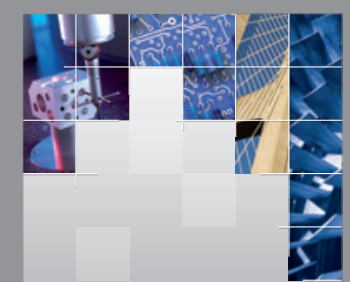

\section{Enfincering}
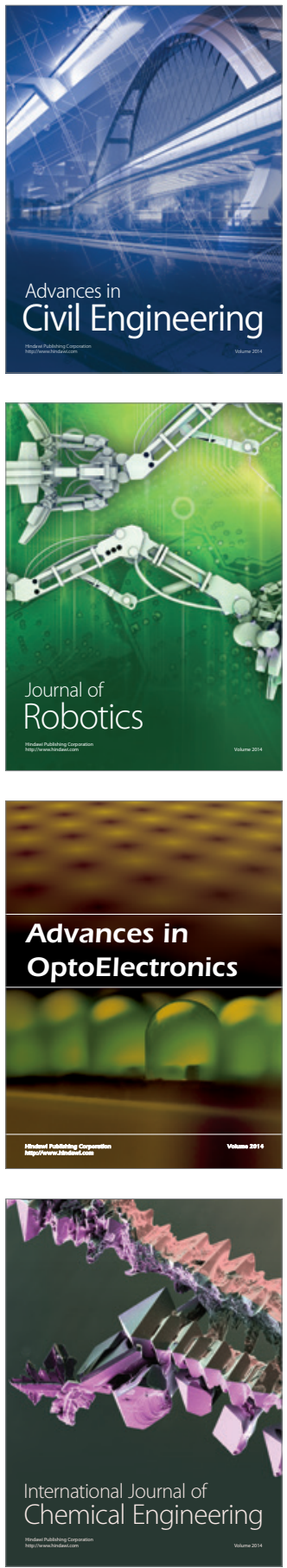

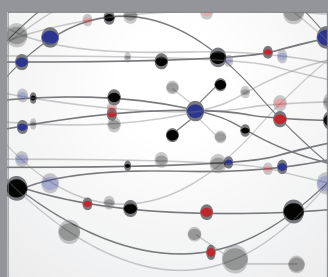

The Scientific World Journal

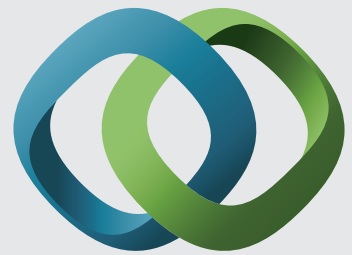

\section{Hindawi}

Submit your manuscripts at

http://www.hindawi.com
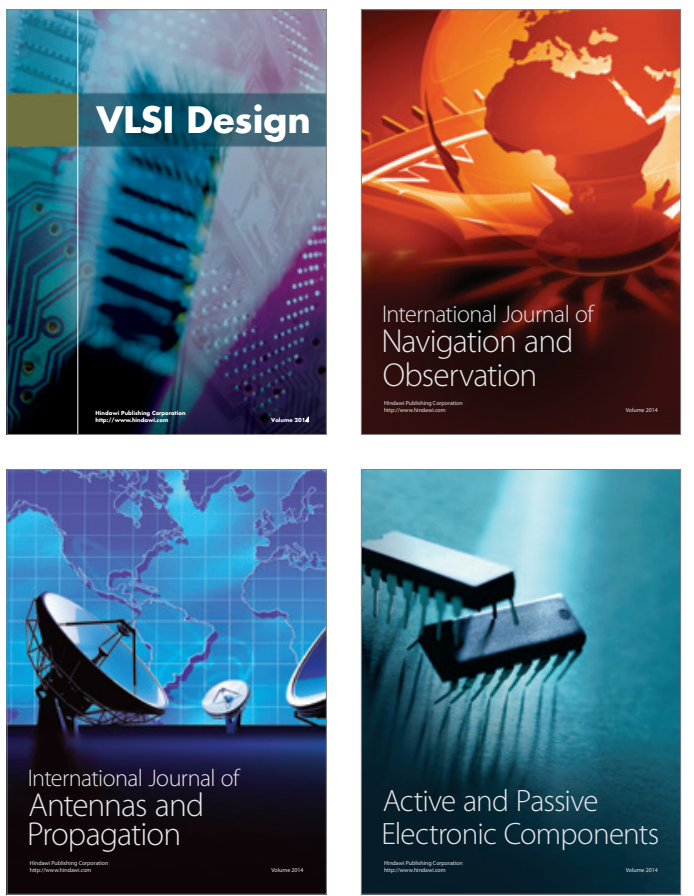
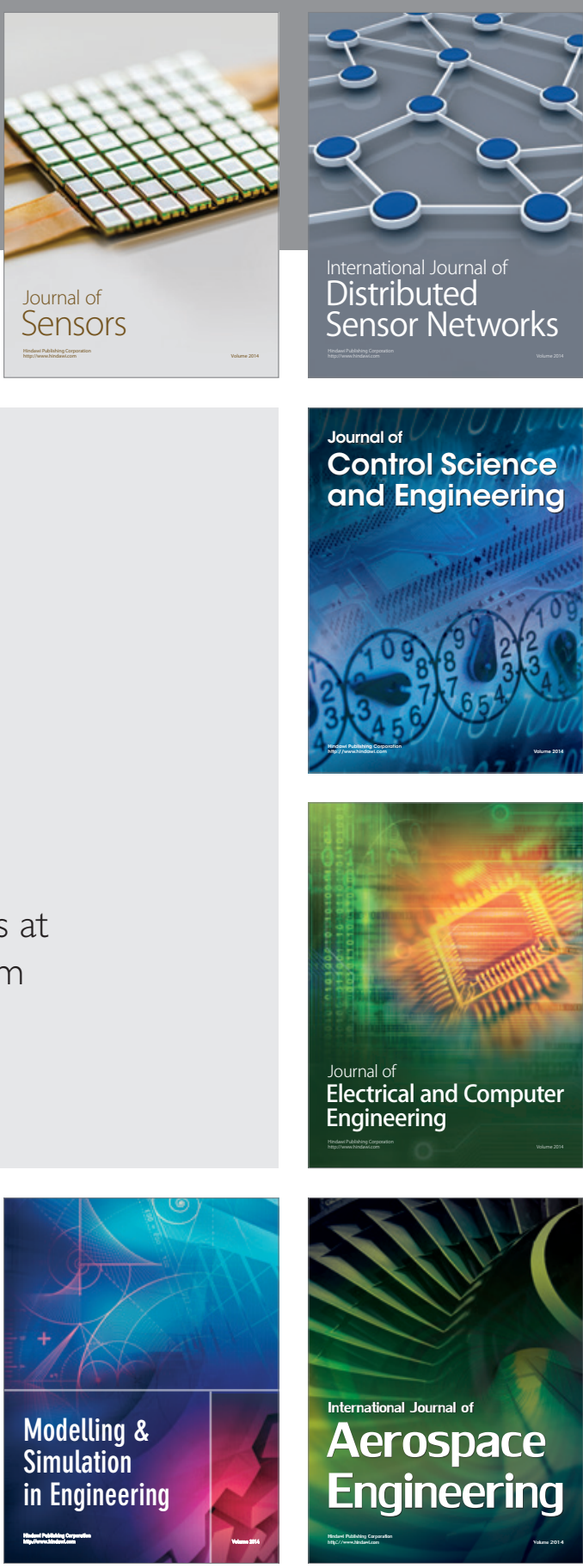

International Journal of

Distributed

Sensor Networks

Journal of

Control Science

and Engineering
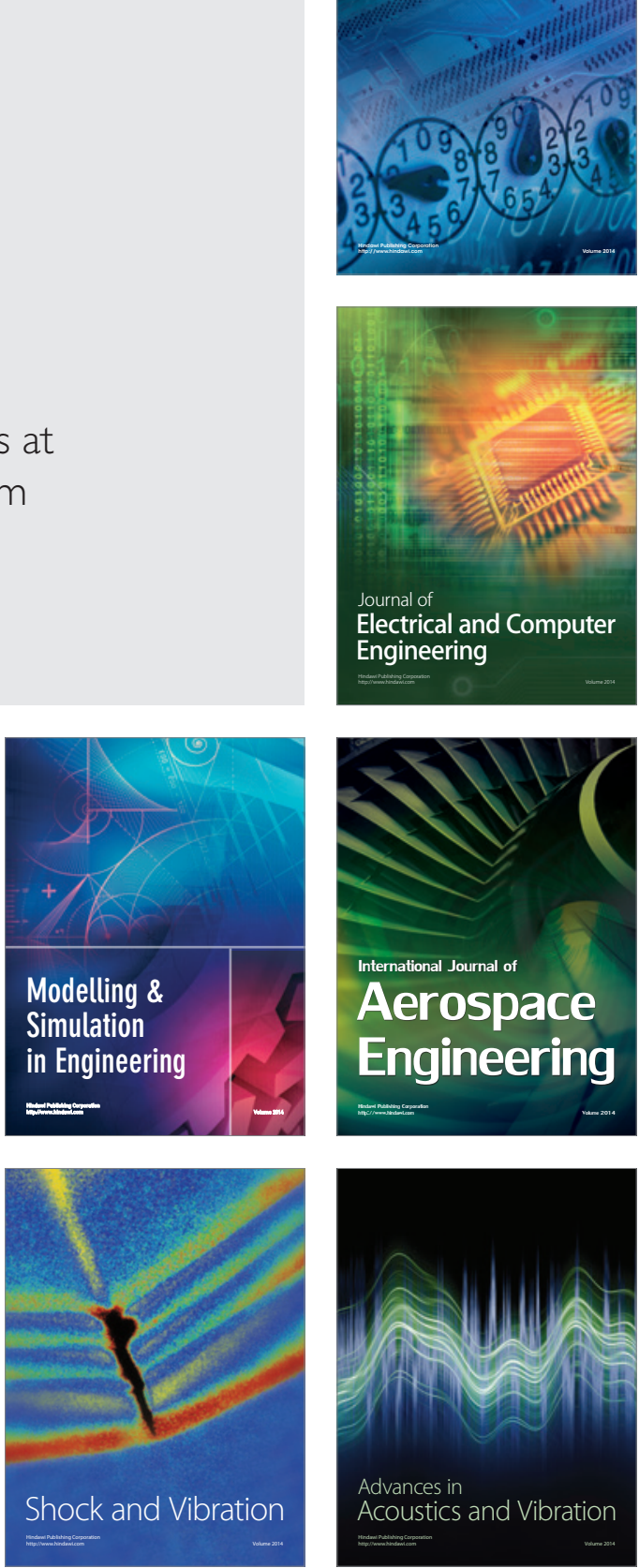